\title{
Transformation of the Management of Industrial Companies in the Context of Digitalization
}

\author{
Alla V. Nikonorova $\left.{ }^{1 *[O R C I D} 0000-0003-4254-0980\right]$, \\ Vera G. Aleksakhina 2[ORCID 0000-0001-5559-5863], \\ Olga P. Ivanova ${ }^{3[O R C I D}$ 0000-0002-9563-4166]
}

\author{
${ }^{1}$ Moscow S.U. Witte University, Moscow, Russia \\ ${ }^{2}$ LEONOV Moscow Region University of Technology, Korolev, Russia \\ ${ }^{3}$ Yaroslav-the-Wise Novgorod State University, Veliky Novgorod, Russia \\ nikonorova-av@mail.ru
}

\begin{abstract}
Management of industrial enterprises is changing significantly in the context of the development of digital technologies. The article examines the directions of management development in modern conditions of digital transformation, explores the possibilities of using new technologies to improve the organization's management system. The strategic technological directions, their role and methods of interference in the management system of industrial enterprises have been studied. The active development of digital technologies simultaneously with the destruction of existing systems creates conditions for the development of promising projects based on innovative ideas and technologies. The introduction of innovations based on the capabilities of digital technologies has become an effective tool for increasing efficiency in Such conditions provoked a redistribution of shares between participants in a competitive market. Changes in technology and the development of scientific and technological progress over time cause the transformation of the entire market. Currently, many economic chains have been destroyed or changed; in such conditions, domestic industrial enterprises find themselves in a difficult situation. Currently, many industrial enterprises occupying leading positions in the world market are engaged in independent development and development of technologies in order to maintain their market positions and create a vector for further development in their field.
\end{abstract}

Keywords: digital economy, information technologies, digital development, industrial enterprises, digital transformation, technological trends

\section{INTRODUCTION}

The changes caused by the digitalization of the economy are observed in all areas, the role and value of information and knowledge is increasing, and the intellectualization of production factors is observed.

Industries and companies that are quick to implement innovative ideas gain a significant competitive advantage in the marketplace in the current environment of vigorous technological change. This situation is becoming even more acute in the context of globalization. However, not only implementation, but also the actual search for information about new developments takes a lot of time [1].
The development of digital technologies significantly affects the management systems of industrial companies, but the issues related to the transformation of the management of industrial companies have been insufficiently studied.

The purpose of this article is to study tools that can be used to improve the efficiency of the industrial enterprise management system in the context of active digitalization. To achieve this purpose, it is necessary to answer the following scientific questions:

- How are technological trends influencing industrial management?

- What are the possibilities of using new 
technologies to improve the management system of an industrial enterprise?

- What directions of management development should be adhered to in the modern conditions of digital transformation?

The use of digital technologies makes it possible to conduct management activities and work with consumers in real time, and the introduction of information technologies opens up wide opportunities for business development and helps to increase the efficiency of actions taken [2].

The emergence of new technical solutions provokes not only the modernization of production, but also changes in the management processes of industrial enterprises.

\section{MATERIALS AND METHODS}

Enterprise management processes are changing significantly in the context of rapid technological development. Digital transformation and changing economic conditions are the cause of both the destruction of existing economic ties and the creation of new ones.

This study aims to address a gap in research on the impact of digitalization on the management of industrial companies.

The methods of deduction and induction, the cause-and-effect relationship identification, the combination of analysis, synthesis, and structuralorganizational approach were applied to explore the processes of changing management in industrial enterprises.

Active study of external environment helps to create the basis for further survival in new conditions [3]. Identification of innovations suitable for implementation in a particular organization is a complex task. Active development of information technologies and their application in various fields of activity create prerequisites for further growth of the companies [4].

The fact is that innovations derived from new knowledge are accompanied with high costs and risks, which may significantly hamper the production of knowledge and reduce level of satisfaction with innovation of economic agents.

Information technologies penetrate into all aspects of functioning of an industrial enterprise. Their introduction into production processes increases the accuracy of operations, positively affects the efficiency of processes, and leads to an improvement in the economic indicators. Their use makes it possible to model the processes of introducing new, previously non-existent, innovative technologies. The changes cause the need to adapt the management system to the new conditions, to monitor and analyze the tendencies in the development of technologies and study the possibilities of their implementation in the practice of enterprise management.

Timely receipt and analysis of information about technological trends makes it possible to quickly respond to changes taking place in the market, make appropriate management decisions. The study of technology development trends helps in navigating the market in a correct manner, choosing the right direction for development.

\section{RESULTS}

Digitalization significantly widens the possibilities in using new technologies for improving management system of an industrial enterprises. It gives the opportunities that had not existed before. For example, managers can presently fulfill their daily duties from any physical place, not only from their usual and permanent workplace.

The work on the analysis of strategic technology trends is of great interest for numerous companies and consulting agencies. For example, the researchers of such a well-known global research and advisory firm as Gartner Inc. discerned such top nine strategic technology trends for 2021 as [5]:

- Internet of Behaviors;

- Total experience;

- Privacy-enhancing computation;

- Distributed cloud;

- Anywhere operations;

- Cybersecurity mesh;

- Intelligent composable business;

- AI engineering;

- Hyper automation.

All these trends are not only observed in development of technologies, their influence is increasing in the corresponding management systems of industrial enterprises.

For the purpose of rapid adaptations for changing conditions and seeking new innovative ways for increasing the competitive advantages of the 
enterprise it is proposed to develop and implement on practice a system of preliminary assessment of innovative technologies.

Schematically, it is possible to characterize the process of adaptation of trends in the development of technologies to the management system of the industrial enterprises as follows (Figure 1).

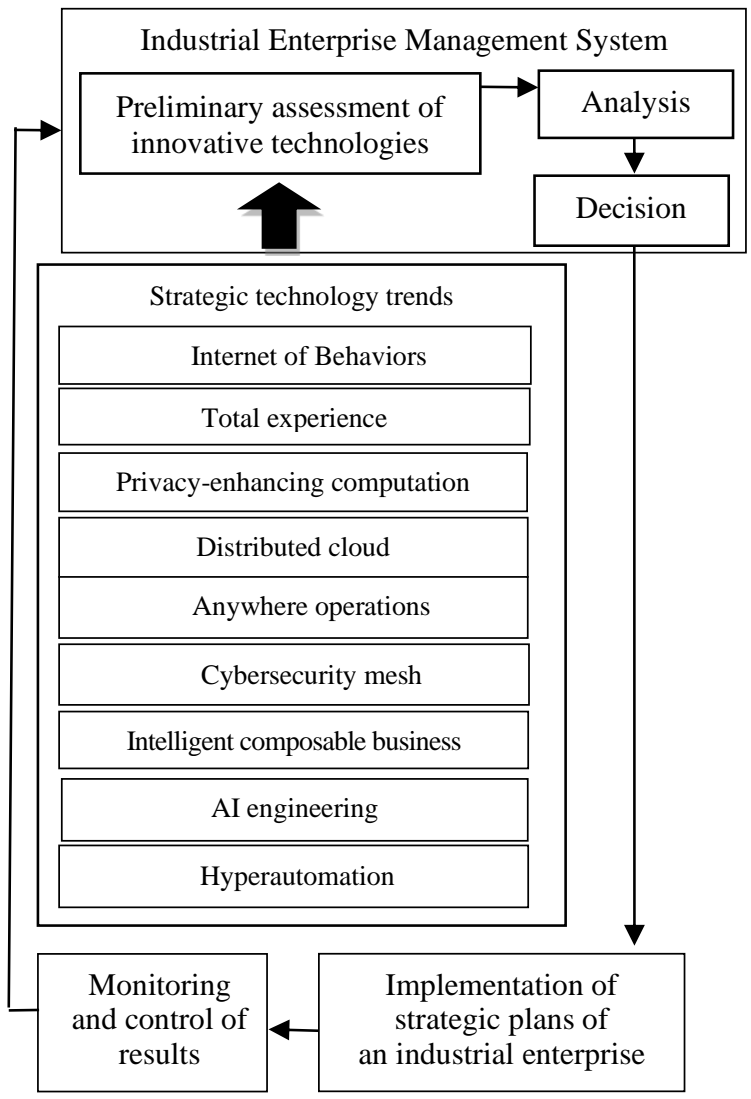

Figure 1. The model of industrial enterprises management with regard to the strategic technology trends

Source: Compiled by the authors

Development and implementation of systems of preliminary assessment could eliminate contradictions between interests of the individuals and producers, create conditions for the economic activity of consumers, induce rise in demand for goods produced by industrial enterprises.

In modern conditions, the competitive struggle between industrial enterprises for leadership in new markets currently begins at the level of ideas [6]. Their implementation depends on the management of industrial enterprises that make decisions regarding the directions of further innovative development [7].

Active participation in the process of developing and implementing innovative technologies is the key factor for enterprises for preserving, sustainably development, and gaining leading positions in the market [8]. However, the costs of implementing innovations are still quite high in comparison to the benefits obtained from their application. Practice shows, however, that only the most recent developments are particularly expensive, the cost of previous-generation technologies reduces significantly over the time.

The consequence of the development of technologies reveals in the increase in the efficiency of the enterprise management system, as technological cycles require less time, there are fewer failures of production processes, it takes less time to eliminate repair and maintenance of equipment [9].

Understanding the possibilities of development of an industrial enterprise in the field of management, adaptation of its production cycles and processes to the current situation, installation of modern production equipment and continuous work with the manufactured product is an effective competitive tool for an enterprise. Tracking emerging technological trends allows domestic industrial enterprises to take steps to resolve emerging problems at an early stage.

\section{DISCUSSION}

The formation of an industrial enterprise management system is influenced by external conditions that change with the development of strategic technological trends and active scientific and technological progress. The result of these changes is the adjustment of the strategic plans of enterprises, which are also transformed taking into account the prospects for the further development of the external environment [10] and the possibilities for the development of the enterprise in the market.

The Internet of Behavior technology makes it possible to work with data on human behavior obtained from various sources. The behavior of the Internet of Behavior technology is similar to the Internet of Things and involves connecting people to the Internet using special devices on an ongoing basis. This technology is primarily focused on changing human behavior. The introduction of the Internet of behavior in the activities of industrial enterprises contributes to obtaining information about the results of the work of employees in real time, increases the controllability of processes. However, the development of Internet behavior is 
inextricably linked to ethical and social dimensions. It should be borne in mind that this can lead not only to a positive economic effect, but also to negative consequences, such as rapid professional burnout, a decrease in the level of information security of an individual, an increase in the level of anxiety in society.

Total experience can be widely used in the activities of industrial enterprises. Working with generalized information received from a large number of both employees and consumers of final products helps to avoid typical mistakes, make the most rational changes, transform knowledge into results, improve feedback, and as a result, the manageability of the entire system.

The issue of safety has always been of paramount importance for industrial enterprises. In the modern conditions of the introduction of digital technologies, the need to develop protection mechanisms has increased significantly. The general trend in the development of computing that increases privacy is also relevant for industrial enterprises. The development of privacy-enhancing computation is aimed at increase in the level of protection of information formed in the process of managing industrial enterprises.

The use of a distributed cloud may also be applicable for industrial enterprises. Distributed cloud technology involves storing data on various servers distributed in the network. As for administration, updating and architecture management, these functions remain within the responsibility of the provider of public cloud services. Distributed cloud technology is directly related to computing that increases privacy, and therefore the development of these technologies should take place in parallel and simultaneously.

The development of technologies that allow anywhere operations has a positive impact primarily on the management of industrial enterprises. It significantly increases the ability to control processes, eliminate failures, facilitates adaptation to changing conditions, and expedites decision-making processes.

Currently, many elements are located outside the traditional security perimeter of an industrial enterprise. The creation of a cybersecurity mesh contributes to improving security in the conditions of a new reality, allows to create a new, more expanded security perimeter, it assumes a distributed architectural approach to scalable, flexible and reliable cybersecurity management. The cybersecurity mesh applies a more flexible approach to security, it identifies a person, thing or product and determines their security perimeter.

The development and implementation of intelligent composable business in the activities of industrial enterprises can contribute to a significant increase in the efficiency of management decisions. This technology is focused on more efficient work with information, its better collection, deeper analysis, and a quick response to the results of such analysis. It accelerates the introduction of significant changes in the processes, allows them to adapt to the current situation in a short time. The development of this technology also creates conditions for more autonomous operation of individual elements, allows timely identification and elimination of inefficient processes. The introduction of the technology of intelligent composable business at industrial enterprises exerts creation of conditions for ensuring the coordinated work of individual, indirectly related to each other, structural units and a more rational use of resources.

The use of artificial intelligence engineering in industrial enterprises can contribute to improving productivity and reliability, solving problems with scaling and interpretability of artificial intelligence models. Work in the field of development of artificial intelligence engineering contributes to reducing the costs of developing, implementing and using software and services related to the functioning of artificial intelligence. In the field of industrial enterprise management, the use of artificial intelligence technology can be useful in solving routine tasks, for collecting, processing and generalizing primary data, for obtaining objective information about production processes on the basis of which management decisions can be made in the future.

Hyperautomation plays a special role for industrial enterprises. Over the past decades, both foreign and domestic companies have been working on improvement of production processes automation. The development of digital technologies brings this work and its results to the new level. The emergence of new technologies contributes to the reduction of resources required for the implementation of production cycles by optimizing processes, increasing their consistency with each other, using new or additional features. Hyperautomation involves the automation of everything that can be automated, it contributes to a more rational use of resources, creating conditions for effective management activities. 
Tracking trends in technological development provides an opportunity for enterprises to adjust their strategic plans promptly, to develop in the rate corresponding to the changing environmental conditions.

\section{CONCLUSION}

Management of industrial companies is actively transforming to correspond the conditions of digitalization processes. Digitalization of the economy have already significantly changed the socio-economic relations within society. Due to the fact that the changes can eventually lead to both positive and negative results, the introduction of innovations requires a comprehensive analysis, including forecasting the development of the changing situation.

The fulfilled research has a practical importance for industrial enterprises, as its results can be used for the purpose of improvement of a management system, they can also be of help for facilitating the decision-making process, and for determination of the directions for future development.

The aim of the research is achieved; all the answers to the questions raised in the beginning of the article are given. The influence of the technological trends on management of industrial enterprises is investigated. The possibilities of using new technologies for improving management system of an industrial enterprises are defined. The directions of management development in modern conditions of digital transformation are designated.

The deep transformation of the domestic economy, which has become the result of the active development of digital technologies, forces companies to adapt to new conditions. The use of digital technologies makes it possible not only to reduce the duration of work, it expands the possibilities of working with large amounts of information, facilitates the decision-making processes, and helps in improvement of the management system.

\section{AUTHORS' CONTRIBUTIONS}

Alla V. Nikonorova, Olga P. Ivanova: development of the concept of the article, analysis of trends and refinement of the presented model, participation in the preparation of the draft text; preparation of the final version of the article. Vera G. Aleksakhina: development of the goal and objectives of the study; collection, analysis and interpretation of data; participation in the preparation of the draft text.

\section{REFERENCES}

[1] A. Nikonorova, D. Morkovkin, N. Isaichykova, V.N. Nezamaikin, "Improvement of innovative infrastructure as a means of economic development", in Proceedings of the 3rd IC on Economics, Management, Law and Education, Advances in Economics, Business and Management Research, 2017, vol. 32. pp. 1-4. DOI: https://doi.org/10.2991/emle-17.2017.1

[2] M.Y. Veselovsky, A.V. Nikonorova, A.A. Stepanov, N.L. Krasyukova, I.V. Bitkina, "The development of innovative startups in Russia: the regional aspect". Academy of Strategic Management Journal, 2017, vol. 16(S1). pp. 197-208.

[3] A.V. Nikonorova, P.V. Stroev, D.E. Morkovkin, O.N. Bykova, N.I. Isaichikova, A.A. Kvak, O.O. Skryabin, "Development of innovations monitoring system and its implementation in practice of commercial companies", AD ALTA: Journal of Interdisciplinary Research, 2019, vol. 9(2). pp. 233-236.

[4] V.M. Tumin, A.V. Polyarus, S.N. Lomachenko, A.S. Troshin, S.Y. Doroshenko, "The identification of regional competitiveness potentials", Biosciences Biotechnology Research Asia, 2015, vol. 12(1), pp. 445-451. DOI: https://doi.org/10.13005/bbra/1684

[5] P. High, "Gartner's Top Nine Strategic Tech Trends For 2021", 2020. Retrieved from https://www.forbes.com/sites/peterhigh/2020/10 /26/gartners-top-nine-strategic-tech-trends-for$2021 /$ ?sh $=5 \mathrm{~d} 7 \mathrm{a} 67 \mathrm{e} 821 \mathrm{f} 6$

[6] M.Y. Veselovsky, M.A. Izmailova, L.A. Yunusov, I.A. Yunusov, "Quality of digital transformation management on the way of formation of innovative economy of Russia", Quality - Access to Success, 2019, vol. 20(169). pp. 66-71.

[7] A. Robb, R. Seamans, "The role of R\&D in entrepreneurial finance and performance", 2017. Retrieved

from https://www.papers.ssrn.com/sol3/papers.cfm?a bstract_id=2341631

[8] A. Groen, G. Cook, P. Sijde, "New TechnologyBased Firms in the New Millennium". Bingley, UK: Emerald, 2017. 
[9] K. Yeung, “Algorithmic Regulation: A Critical Interrogation”, TLI Think! Paper 62/2017; Regulation \& Governance; King's College London Law School Research Paper, 2017, vol. 2017-27. Retrieved from https://www.ssrn.com/abstract=2972505
[10] A. Zomorrodian, "New Trends on Strategic Planning: Virtual Environment, Tech Innovation, Globalization \& Organizational Performance", 2017. Retrieved from https://www.dx.doi.org/10.2139/ssrn.2927486 